\title{
SISTEMA POLÍTICO MULTINIIVEL NO BRASIL: UMA ANÁLISE DA RELAÇÃO ENTRE TRANSFERÊNCIAS INTERGOVERNAMENTAIS E REduÇÃo das desigualdades territoriais no Estado do Paraná ${ }^{\mathrm{I}}$
}

\section{MULTI-LEVEL GOVERNMENT STRUCTURES IN BRAZIL:}

THE RELATIONSHIP BETWEEN INTERGOVERNMENTAL TRANSFERS AND A REDUCTION IN REGIONAL INEQUalities in the STATE of Paraná

\author{
Carin Caroline Deda ${ }^{\text {A, B, C, E, F }}$ \\ Samira KauchakJe ${ }^{\text {A, E, F }}$ \\ Pontifícia Universidade Católica do Paraná, Programa de Pós-Graduação em Gestão Urbana, Curitiba, PR, Brasil
}

R E S U M O : O objetivo deste artigo é analisar os efeitos na taxa de crescimento do desenvolvimento dos municípios paranaenses exercidos pelo grau de dependência das transferências intergovernamentais, representadas sobretudo pelo Fundo de Participação dos Municípios (FPM), bem como pelas despesas de investimento. Para tanto, é empregado um modelo econométrico de regressão baseado no método de Mínimos Quadrados Ordinários (MQO). A amostra é composta de 349 municípios paranaenses no período de 2002 a 2013. Os resultados indicam uma relação positiva entre o grau de dependência dos orçamentos dos governos locais quanto ao FPM e à taxa de crescimento do índice de desenvolvimento, ou seja, o aumento da dependência das transferências estimula a evolução do desenvolvimento dos municípios paranaenses. Por fim, o artigo, com base nos dados apresentados, ratifica a importância da aplicação de mecanismos de coordenação das açóes entre os diversos níveis de governo para a efetiva viabilizaçáo do processo de redução das desigualdades intermunicipais.

P A L A V R A S - C H A V E : transferências intergovernamentais; Fundo de Participação dos Municípios; grau de dependência; governo multinível; municípios paranaenses.

A BS TR A C T: The objective of this article is to analyze the effects on the growth rate of development in municipalities in the state of Parana exercised by the degree of dependence on intergovernmental transfers represented by the Municipal Participation Fund (MPF), as well as by investment expenses. Hence, we have used an econometric regression model with the Ordinary Least Squares (OLS) method. The sample is composed of 349 municipalities in Parana from 2002 to 2013. The results have indicated a positive relationship between the degree to which local government budgets depend on the MPF and the growth rate of the development index, I.e., an increase in dependence on transfers stimulates the development process in municipalities in Paraná. Finally, it may be understood that applying mechanisms to coordinate actions among the different levels of government constitutes an important role in enabling the process of reducing inter-municipal inequalities.

KE Y W O R D S : intergovernmental transfers; Municipal Participation Fund; degree of dependence; multilevel government; municipalities in Paraná.

Contribuição de cada autora: A. fundamentação teórico-conceitual e problematização; B. pesquisa de dados e análise estatística; C. elaboração de figuras e tabelas; D. fotos; E. elaboração e redação do texto; F. seleção das referências bibliográficas.

1 Este estudo foi apresentado no 24 Congresso Mundial de Ciência Política - IPSA, que ocorreu em Poznań, Polônia, entre 23 e 28 de julho. As autoras agradecem as críticas e sugestões de dois pareceristas anônimos da RBEUR, as quais contribuíram para a melhoria deste trabalho. DOI: https://doi.org/10.22296/2317-1529.2017v19n3p530 


\section{INTRODUÇÃO}

A Constituição Federal de 1988 favoreceu o processo de descentralização fiscal da esfera federal para as esferas estaduais e municipais, tendo como justificativa a busca de uma maior eficiência dos gastos públicos, o que proporcionou, aos municípios brasileiros, maior autonomia financeira e responsabilidade fiscal. Em função do caráter diverso e das particularidades dos entes subnacionais de uma federaçáo, como é o caso dos municípios brasileiros, as desigualdades inter-regionais são intensas. As transferências intergovernamentais podem ser empregadas como um importante mecanismo de equilíbrio das finanças públicas; com isso em vista, o regime federativo brasileiro utiliza essas transferências com o intuito de corrigir as disparidades existentes entre os entes subnacionais, visando à eficiência do gasto público.

Apesar de a finalidade primordial das transferências ser a equalização das receitas, transferindo recursos em prol do equilíbrio socioeconômico, elas desestimulam a maximização das capacidades tributárias dos entes federativos, uma vez que permitem que os gestores públicos se apoiem em transferências, especialmente nos casos de municípios com uma pequena população e uma baixa capacidade fiscal. Por sua vez, isso implica um maior grau de dependência orçamentária.

É esperado que as transferências obrigatórias se destinem aos municípios mais pobres. Por exemplo, o objetivo da principal transferência constitucional da União destinada aos municípios - isto é, o Fundo de Participação dos Municípios (FPM) - é a diminuição das desigualdades regionais a partir da distribuição de recursos em favor dos municípios menos favorecidos. De acordo com Gibson, Calvo e Falleti (2004) e Amorim Neto e Simonassi, (2013), quando isso não ocorre, o federalismo fiscal no Brasil acaba por apresentar-se como predominantemente realocativo, operando num sistema em que os municípios mais desenvolvidos recebem mais recursos - fato que contraria a ideia de distribuição.

Nesse contexto, um fator que merece atenção é a abordagem do sistema político multinível, que promove uma crescente expansão da interdependência entre níveis de governo intervindo nos vários níveis territoriais. A coordenação e a articulação de açôes entre a União, os estados e os municípios - com vistas a equilibrar as tendências de cooperação e competição e a regulamentação e a fiscalização de políticas pela Uniâo para, assim, estimular a uniformidade dos gastos municipais - são mecanismos que impulsionam e possibilitam o desenvolvimento, contribuindo para a diminuição das desigualdades territoriais.

As transferências intergovernamentais como meio de promover a equiparação regional podem ter como efeito o aumento da dependência em relação a elas por parte dos municípios, sem a contrapartida do uso eficiente dos recursos. A análise do caso do Paraná fornece evidências para essa discussão, pois, em tal estado, há uma diversidade regional significativa, um tanto análoga às diversidades socioeconômicas nacionais.

Considerando esse quadro, o objetivo deste artigo é analisar os efeitos tanto do grau de dependência dos orçamentos municipais em relação ao FPM quanto das despesas de investimento sobre o desenvolvimento dos municípios paranaenses. Ele pretende responder se a dependência das transferências promove a diminuição das desigualdades intermunicipais. Para tanto, foi utilizada a técnica estatística de regressão econométrica com o método de Mínimos Quadrados Ordinários (MQO), tendo como amostra todos os municípios que apresentaram dados para as variáveis 
de análise no período estudado, isto é, de 2002 a 2013. A fim de complementar as análises, são usados gráficos de dispersão para o Estado do Paraná, representado por suas 10 mesorregiōes geográficas e municípios de maior nível populacional.

\section{SISTEMA POLÍTICO MULTINÍVEL E SEUS DESAFIOS}

A instalação de um sistema político multinível em uma nação promove a expansão da interdependência entre níveis de governo, intervindo, assim, nos vários níveis territoriais. Diversas competências são atribuídas aos diversos níveis de governo, como habitação, assistência, educação e saúde e também problemas concernentes à questão tributária e fiscal, por exemplo, a responsabilidade de arrecadar tributos e gastá-los adequadamente (ARRETCHE, 2005).

A Constituição Federal de 1988 favoreceu o processo de descentralização fiscal da esfera federal para as esferas estaduais e municipais, o que atribuiu maior autonomia financeira, compromisso fiscal e responsabilidade na oferta de bens públicos para todos os entes federativos. Com as alteraçóes, espera-se que a descentralização promova a prestação eficiente dos serviços públicos pelos governos locais, tendo como resultado o crescimento econômico e a diminuição das desigualdades territoriais; todavia, a existência de vários níveis de governo atuando no mesmo território tende a promover vantagens e inconvenientes da descentralização fiscal, algo que faz com que a relação entre descentralização e crescimento econômico se torne ambígua (ESTEBAN-LALEONA; FRUTOS-MADRAZO; MIGUEL-BILBAO, 2011).

Conforme Abrucio e Franzese (2007, p. 1), “[a] Federação é uma forma de organização político-territorial baseada no compartilhamento tanto da legitimidade como das decisóes coletivas entre mais de um nível de governo". Já o federalismo fiscal é definido, segundo Prado (2007, p. 2), como "o conjunto de problemas, métodos e processos relativos à distribuiçấo de recursos fiscais em federaçóes, de forma tal que viabilizem o bom desempenho de cada nível de governo no cumprimento dos encargos a ele atribuídos". Os governos subnacionais receberam com o federalismo fiscal brasileiro maior autonomia e também maiores obrigaçóes.

Arretche (2010) argumenta que a autonomia política dos governos subnacionais compromete a capacidade de integração territorial e social do Estado e que a interação entre governos centrais e locais pode implicar o surgimento de desigualdades entre os entes federativos:

[...] estados federativos que concentram autoridade regulatória na União criam mecanismos institucionais que operam na direção da redução das desigualdades. Contudo, a possibilidade de divergência dos governos locais, uma característica intrínseca de estados federativos, tende a produzir mecanismos que operam no sentido da divergência de políticas entre jurisdiçóes. Consequentemente, estados federativos que combinam regulaçáo centralizada e autonomia política dos governos locais tendem a restringir os patamares da desigualdade territorial (ARRETCHE, 2010, p. 591).

Um fator que explica esse resultado é a discordância entre parte das unidades constituintes da federação, com a consequente criação de mecanismos institucionais 
que favorecem a diversidade de políticas: possuindo maior autonomia, as jurisdiçôes podem discordar entre si ou até mesmo com o governo local, resultando, por conseguinte, em desigualdade nas políticas implementadas. Nesse tipo de caso, o papel regulatório e redistributivo do governo central é essencial para obter a cooperação das jurisdições entre si. De acordo com a Arretche (2010), há um padrão na prioridade de gastos dos municípios brasileiros explicados pela relação central-local. As políticas que são regulamentadas e supervisionadas pela União, como educação e saúde, apresentam uma prioridade nos gastos municipais, enquanto as políticas não reguladas operam no sentido contrário, apresentando disparidade nos valores de gasto per capita. ${ }^{2}$ Desse modo, pode-se inferir que a função de regulação nacional é um importante elemento para a reduçáo das desigualdades territoriais.

Mecanismos institucionais de equilíbrio das finanças públicas, como as transferências fiscais, deveriam buscar a equidade entre as diversas regióes do país, operando em favor das regióes mais pobres. Entretanto, em detrimento dessa busca, observa-se uma conexão entre fatores políticos e alocação de fundos públicos, ou seja, há uma natureza política nas transferências. Assim, de acordo com Amorim Neto e Simonassi (2013), nas decisóes de direcionamento das transferências, aos atores políticos, são preferíveis as localidades mais relevantes politicamente do que as que têm uma intensa necessidade de recursos. Segundo Gibson, Calvo e Falleti (2004), quando a transferência de recursos se dá por interesses políticos, em detrimento das necessidades econômicas dos entes subnacionais, ocorre o federalismo realocativo, que se sobressai, em tais situaçốes, em relação ao federalismo proporcional.

Os fatores políticos que dirigem as transferências fiscais estão relacionados com o processo orçamentário. As regras para apresentação de emendas ao orçamento limitam a capacidade de cada parlamentar de influenciar na distribuiçáo de recursos de acordo com suas preferências geográficas e eleitorais. $\mathrm{O}$ Executivo brasileiro tem um papel central no processo orçamentário, podendo vetar o orçamento aprovado e tendo, além disso, uma margem discricionária em sua execução. Para as transferências discricionárias, essa margem é, na norma, irrestrita, o que possibilita ao Executivo decidir o montante e a sua destinação. Fica clara, pois, a importância de "[...] utilizar os conceitos de autonomia e de mecanismos de coordenação para identificar as relaçôes entre os níveis de governo com relação às distintas dimensôes de autoridade [...]" (ARRETCHE, 2005, p. 70).

A autonomia dos governos locais é uma característica presente no sistema brasileiro, todavia a arrecadação de tributos e a execução de políticas dos governos subnacionais são consideravelmente limitadas pelo governo federal. Ou seja, ainda que os entes federativos sejam politicamente autônomos, tal autonomia é afetada pela regulação federal, portanto, "examinar desigualdades territoriais de acesso dos cidadãos brasileiros a políticas públicas requer incluir a regulação federal na análise" (ARRETCHE, 2010, p. 597).

Um dos possíveis benefícios proporcionados pela estrutura governamental de vários níveis é que os governos subnacionais, devido à maior proximidade estabelecida com seus administrados e ao conhecimento de suas preferências e necessidades e também das condiçôes de custos disponíveis em sua regiāo, poderiam suprir em maior medida as deficiências dos indivíduos de suas jurisdiçôes (ESTEBAN-LALEONA; FRUTOS -MADRAZO; MIGUEL-BILBAO, 2011). Estudos sobre a relação entre proximidade e suprimento de necessidades apresentam resultados controvertidos, seja para sistemas federados, seja para unitários. De todo modo, deixam claro que o papel dos governos
2 Arretche (2010) apresenta dados de percentuais de gastos com saúde, educação, habitação e urbanismo e transporte para os municípios brasileiros. Em seu trabalho, fica claro que políticas reguladas (saúde e educação) têm alta prioridade na alocação dos gastos municipais, ao passo que políticas não reguladas (habitação e urbanismo e transporte) não têm prioridade de gasto. 
locais é relevante no sentido de propiciar serviços públicos; o desafio é evitar a sobreposição de competências entre os vários níveis de governo e de atribuição de funçóes, responsabilidades e autoridades para cada nível (BLANCO GARCÍA et al., 2012).

As relaçóes entre os níveis de governo são caracterizadas por cooperação e competição. As "[...] federaçôes devem, primeiramente, equilibrar as formas de cooperação e competição existentes, levando em conta que o federalismo é intrinsecamente conflitivo" (ABRUCIO, 2005, p. 44). A cooperação contribui para o equilíbrio de uma federação, promovendo a diminuição das desigualdades territoriais; nessa estrutura, as decisões são compartilhadas pelos entes federativos. Há que se ter em conta que a cooperação, se mal dosada, pode resultar mais em subordinação do que em parceria, além de poder enfraquecer o impulso inovador dos níveis de governo. Por seu turno, as formas de competição favorecem a busca por inovação e melhor desempenho das gestóes locais, evitando o excesso dos movimentos cooperativos. Todavia, é importante observar que também ocorrem problemas devido ao excesso de competiçáo, como a piora na questão redistributiva e a guerra fiscal entre os governos subnacionais (ABRUCIO, 2005). Sendo assim, o equilíbrio das tendências de cooperação e competição requer a coordenação das ações dos diversos níveis de governo.

Abrucio (2005) argumenta que, para os entes federativos náo concentrarem poder excessivamente, prejudicando a autonomia dos demais, é importante que haja um controle mútuo de fiscalização para coordenar as açóes dos níveis autônomos de governo. Da mesma forma, Palotti e Costa (2011) salientam a importância da implementação de políticas públicas que intentem assegurar a integridade política e a autonomia dos vários níveis de governo, de modo a coordenar açóes que visem ao alcance de fins comuns. Isso é fundamental porque, com a multiplicidade de atores no sistema federativo, existe o problema da visão territorial própria de cada órgão que exerce o poder nas políticas públicas - visão que não necessariamente se articula com a de outros órgãos. Por essa razão, há sempre o desafio de coordenar diferentes atores com objetivos e estratégias distintos.

\section{TRANSFERÊNCIAS INTERGOVERNAMENTAIS: O FPM NO ORÇAMENTO MUNICIPAL}

Com o processo de descentralização e o federalismo fiscal favorecido pela Constituição de 1988, os entes federativos passaram a ter maior autonomia e responsabilidade fiscal e também maior responsabilidade na oferta de bens e serviços públicos. Conforme Arretche (2005), as bases de autoridade dos governos locais foram alteradas profundamente a partir da descentralização fiscal; houve a expansão da autoridade local sobre os recursos fiscais e também da autoridade tributária sobre impostos de significativa importância.

Como o Brasil é um país dotado de diferenças entre as jurisdiçóes, apresentando uma forte desigualdade territorial, existe uma série de recursos federais que visam a manter o equilíbrio federativo (SOUZA, 2003). Nesse cenário, destacam-se as transferências intergovernamentais, que sáo uma forma de buscar maior eficiência do setor público no âmbito da implementação de políticas e serviços e representam um mecanismo de equilíbrio das finanças públicas. Elas são pertinentes nos regimes federativos, nos quais a gestão fiscal objetiva, principalmente, tributar e efetuar o dispêndio com equidade e eficiência, adequando a distribuição de recursos. 
As descentralizaçóes das tarefas de execução ocorrem mediante a transferência de recursos, seja da administraçáo federal para unidades federadas, seja daquela para o setor privado. A estrutura descentralizada de governo que as transferências fiscais proporcionam pode ser uma das condiçóes para favorecer a conexão entre a arrecadação tributária e as açôes públicas, a visibilidade das políticas públicas, as exigências da população e o uso dos recursos por governantes.

As transferências intergovernamentais podem ser classificadas em duas grandes categorias: obrigatórias e discricionárias, ou seja, aquelas que decorrem de determinação constitucional ou legal e aquelas que resultam de negociaçôes entre os governos centrais e os governos subnacionais, com a consequente entrega de recursos a outro ente da federação a título de cooperação, auxílio ou assistência financeira.

Em função das diferenças e das características particulares dos entes federativos brasileiros, observam-se desequilíbrios fiscais resultantes da concentração espacial das bases de tributação nos maiores centros e também uma dispersão regional da demanda de bens e serviços públicos. Em sua análise das transferências fiscais, Gasparini e Miranda (2006) apontam algumas razóes para a criaçáo delas, entre as quais estáo a adequação entre a capacidade arrecadatória e a necessidade dos gastos públicos diante das demandas dos entes subnacionais, a minimização das diferenças regionais ao longo do território nacional, o melhor gerenciamento dos recursos públicos em cada uma das três esferas de governo - isto é, a União, os estados e os municípios.

Soares e Neiva (2011) notam que as transferências discricionárias federais são uma importante fonte de receita no orçamento dos estados brasileiros, correspondendo a aproximadamente 3\% do total das taxas e a $9 \%$ do total das transferências constitucionais. No entanto, há diferenças na importância dessas transferências no orçamento de cada estado em funçáo de suas disparidades econômicas regionais. Por exemplo, em Sergipe, as transferências discricionárias representam quase 70\% das taxas coletadas, por seu turno, em Sáo Paulo, elas representam por volta de $0,2 \%$. Isso ocorre devido ao intuito das transferências de corrigir as disparidades regionais, procurando melhorar e aumentar a oferta de bens públicos e garantir o equilíbrio orçamentário das unidades federativas menos favorecidas e com menor capacidade arrecadatória.

Todavia, o caráter redistributivo das transferências federais é controverso, ou melhor, é mais pertinente quando se trata das transferências não discricionárias e controvertido quando se põe em questão as discricionárias, como demonstram as autoras e os autores abordados a seguir.

O caráter redistributivo das transferências não discricionárias é abordado por Soares e Neiva (2011), que observam que, juntos, São Paulo, Minas Gerais e Rio Janeiro, cujo total das taxas de sua competência ultrapassa $50 \%$ do total coletado pelos outros estados, são aqueles que recebem menos de $30 \%$ das transferências constitucionais. Os estados do Nordeste, que recolhem aproximadamente $14 \%$ das taxas, recebem mais de 30\% do total desse tipo de transferência. Arretche e Rodden (2004) também chegaram a uma conclusão semelhante ao tratarem das transferências constitucionais; Gibson, Calvo e Falleti (2004), por sua vez, analisaram os dados do Brasil, Argentina, México e Estados Unidos, encontrando uma moderada relação positiva entre as variáveis gastos não discricionários e pobreza, e uma relaçáo negativa entre tais gastos e a renda per capita.

Em referência às transferências discricionárias, ainda que Soares e Neiva (2011) mostrem que as regióes com menor desenvolvimento econômico recebem uma porcen- 
tagem maior desses recursos (Norte, Nordeste e Centro-Oeste, respectivamente), Gibson, Calvo e Falleti (2004) não encontraram uma relação significativa entre as variáveis gastos discricionários e pobreza nem entre tais gastos e a renda per capita. Para Arretche e Rodden (2004), a distribuição das transferências não constitucionais não beneficia os estados mais pobres e, portanto, "não se pauta por critérios de necessidade”. Nesse sentido, Amorim Neto e Simonassi (2013) e Turgeon e Cavalcante (2014) verificam uma tendência à manutenção das desigualdades inter-regionais, além de demonstrarem que os recursos transferidos aos estados parecem ser dirigidos mais por fatores políticos que por características socioeconômicas das unidades subnacionais ou por critérios de redução das desigualdades inter-regionais.

Os impactos econômicos e políticos das duas grandes categorias de transferências (obrigatórias e discricionárias) são diferentes, pois, ao passo que a função de redistribuição de recursos é operada com as transferências obrigatórias, as transferências discricionárias assumem um papel suplementar e de ajustamento emergencial, sendo que o fator político parece ser mais relevante para elas. Conforme Prado (2001), “[a] orientaçáo para reduzir disparidades ou equalizar a distribuição de receitas é um atributo adicional que as transferências redistributivas podem assumir ou não" (PRADO, 2001, p. 4). Desse modo, as transferências, mesmo que possuam o objetivo redistributivo, podem ou não ter o efeito de reduzir as desigualdades regionais. A maior parte delas é de fato equalizadora, mas há exceçōes, sem contar que esses recursos podem ser submetidos ao jogo político, servindo como moeda de troca para os governos centrais. Prado (2001) aponta que as diversas modalidades de repasses possuem características institucionais distintas. Ele apresenta uma tipologia das transferências, classificadas a partir de três denominaçôes: (i) transferências como instrumento de política fiscal federativa; (ii) transferências no orçamento excedente: legais versus discricionárias; (iii) transferências no orçamento receptor: livres ou vinculadas.

As transferências como instrumento de política fiscal federativa têm os objetivos de devolução tributária, equalização por meio de transferências redistributivas e viabilização de políticas setoriais. No primeiro caso - devoluçáo tributária -, a arrecadação é feita pelos níveis superiores de governo (Estado ou União) e cada jurisdição recebe uma parcela da arrecadaçáo de acordo com sua capacidade fiscal, compensando a concentração da arrecadação em níveis centrais de governo. Embora a função de arrecadação seja apenas dos níveis superiores de governo, cabe ao governo local as receitas geradas em cada ente federativo. O segundo objetivo visa à equalização e à redução das desigualdades regionais por meio de transferências redistributivas. Essas transferências têm caráter de suplementaçáo orçamentária; por meio delas, os níveis superiores de governo redistribuem parte da receita arrecadada, com o intuito de reduzir as disparidades inter-regionais. $\mathrm{O}$ terceiro objetivo busca a viabilização de políticas setoriais decididas nos governos centrais, mas que requerem gerenciamento local.

A segunda classificação feita por Prado (2001) são as transferências no orçamento excedente, instituídas por norma legal ou decidida de forma discricionária. As transferências legais são aquelas cujos critérios e montantes a serem distribuídos estão especificados em lei ou na Constituição. Já as transferências discricionárias têm caráter complementar; são resultado das decisôes orçamentárias anuais dos governos federal e estadual.

Por fim, a última classificaçấo - transferências no orçamento receptor: livres ou vinculadas - é definida segundo o grau de condicionalidade que o uso de recursos terá para os governos receptores. Há diferença entre os recursos que podem ser livres 
e os recursos vinculados. As transferências livres estão à disposição dos governos locais, propiciando-lhes maior liberdade de escolha; já as transferências vinculadas são recursos destinados a complementar ou a compor integralmente programas de políticas públicas, elas buscam uniformizar os dispêndios entre jurisdiçóes heterogêneas.

Neste estudo, devido ao caráter redistributivo das transferências constitucionais, como destacam Prado (2001), Soares e Neiva (2011), Arretche e Rodden (2004), entre outros, optou-se por utilizar o Fundo de Participação dos Municípios (FPM), pois ele representa a maior parte das receitas municipais, além de ser a principal transferência constitucional concedida pela União aos municípios.

O FPM foi criado em 1965 por meio da Emenda Constitucional no 18, de 1/12/1965, com o objetivo de suplementar o orçamento dos municípios e de promover o equilíbrio socioeconômico dos entes federativos. Atualmente, o seu montante é constituído de $23,5 \%$ da arrecadação líquida do Imposto de Renda (IR) e do Imposto sobre Produtos Industrializados (IPI). Como dispóe a definição adotada pela Secretaria do Tesouro Nacional ${ }^{3}$, o rateio da receita proveniente da arrecadaçáo de impostos entre os entes federados representa um mecanismo fundamental para a reduçáo das desigualdades regionais, visando ao equilíbrio socioeconômico entre estados e municípios.

Segundo Sousa e Arantes (2012), os municípios são os entes federativos com menor capacidade arrecadatória, portanto, necessitam das transferências intergovernamentais:

[...] sendo os municípios o menor ente da federação, são poucas as competências de arrecadação destes, inviabilizando a sua capacidade de cumprir com suas atribuições. Para compensar esse desequilíbrio[,] há a necessidade do uso de transferências dos entes maiores para os menores. E uma dessas transferências recebidas pelos municípios é o FPM proveniente da União (SOUSA; ARANTES, 2012, v. 2, p. 55).

As transferências do FPM compensam a tendência de concentraçáo dos recursos nas regiōes desenvolvidas do país, pois são distribuídas em maior proporção nas regiōes menos desenvolvidas economicamente (SOUZA, 2003). Os recursos do FPM são distribuídos aos municípios de baixo desenvolvimento e advêm, como dito, do IR e do IPI captados em regiôes mais industrializadas e de renda familiar mais elevada. A distribuiçáo dos recursos dessa transferência acontece da seguinte forma: 10\% dos recursos são entregues aos municípios que são capitais de estados; 86,4\%, aos municípios que não são capitais; e 3,6\% deles fazem parte de uma reserva para suplementar a participação dos municípios mais populosos. Predominantemente, são distribuídos conforme o tamanho do município. A princípio, as parcelas são divididas por estado, depois, para cada município (MENDES; MIRANDA; COSIO, 2008). Em síntese, pode-se afirmar que tal receita é uma transferência constitucional de natureza federal com orientação redistributiva (ARRETCHE, 2010).

\section{DEPENDÊNCIA DO FPM}

As transferências federais representam uma importante fonte de receita aos municípios brasileiros, principalmente aos pequenos e médios (SOUZA, 2004). Segundo Bremaeker (2011), a filosofia de distribuição do FPM é a de entregar mais recursos, em valores per capita, aos municípios de menor porte demográfico, sendo que existem dois fatores que justificam essa decisão:
3 Cf. Portal do Ministério da Fazenda. Disponível em: <http://www.tesouro. fazenda.gov.br/pt_PT/ cartilhas-de-transferenciasconstitucionais>. Acesso em: 31 mai. 2017. 
[...] em primeiro lugar, quanto menor o porte demográfico dos municípios, menor é a sua capacidade de consumo e, portanto, menor é a sua participação na distribuição do ICMS estadual [Imposto sobre Circulaçáo de Mercadorias e Serviços]; e, em segundo lugar, quanto menor o porte demográfico dos municípios, menor é a sua arrecadação tributária, não apenas pelo seu menor quantitativo, mas também pelo fato de que os principais tributos municipais têm sua base de tributação no meio urbano [Imposto Sobre Serviço ISS e Imposto Predial e Territorial Urbano - IPTU] (BREMAEKER, 2011, p. 3).

Sousa e Arantes (2012) destacam que o FPM é a principal fonte de receita para muitos municípios. O grau de dependência em relação a esse recurso varia de acordo com o município: alguns dependem extremamente dele; para outros, porém, ele representa apenas uma pequena porcentagem do orçamento municipal. Essa dependência está ligada ao tamanho do ente federativo.

$\mathrm{Na}$ grande maioria dos casos, os municípios menores em relação ao número de habitantes são os que mais dependem do FPM:

No caso dos governos municipais, a alta dependência de receitas de transferências é generalizada. Apenas os municípios mais populosos exibem receitas tributárias e outras receitas correntes um pouco mais significativas. Nos municípios com até 50 mil habitantes, que representam $88 \%$ do total de governos locais, a dependência em relação às transferências supera $80 \%$ da receita total (MENDES; MIRANDA; COSIO, 2008, p. 26).

A Constituição Federal prevê que os entes federativos menos desenvolvidos precisam receber mais recursos para impulsionar o seu desenvolvimento até que consigam equiparar-se aos municípios mais prósperos. No entanto, esse cenário acarreta maior dependência dos municípios de menor dinamismo em relação às transferências, já que são sustentados pelos recursos dos municípios maiores - quanto mais se caminha nesse sentido, mais dependência é gerada (BRITO; MATOS FILHO; COSTA, 2014). Segundo Brito, Matos Filho e Costa (2014), o federalismo e a descentralização fiscal brasileira confirmam esse cenário de dependência, sobretudo em relaçáo ao FPM, na medida em que os dados apontam para a existência de, cada vez mais, uma maior dependência e para a fragilidade de políticas públicas voltadas para a mudança desse quadro. Os autores sublinham que há um paradoxo causado pela estrutura do federalismo brasileiro, uma vez que os municípios têm autonomia política, mas são dependentes das transferências de recursos dos governos central e estadual:

Esse processo pode ser entendido como uma espécie de "Autonomia Dependente", os municípios [operam] como entes federados, com autonomia na tomada de decisão (embora suas açōes sejam reguladas pelo governo central), mas [são] totalmente dependentes de transferência de recursos do governo central e do estadual para composição de suas receitas orçamentárias. É um triste paradoxo causado pelo desajuste do federalismo brasileiro (BRITO; MATOS FILHO; COSTA, 2014, p. 58).

Com isso, cumpre ressaltar, é formado um círculo vicioso em que "cada vez mais os menores municípios ficam à mercê da arrecadação dos maiores, causando um 'desgaste' de ambos os lados” (BRITO; MATOS FILHO; COSTA, 2014, p. 53). 
Para atingir o objetivo proposto, foi estimado um modelo de regressão com o método de Mínimos Quadrados Ordinários (MQO). A fim de dar suporte às análises, foram construídos gráficos de dispersão para averiguar o grau de dependência das transferências, assim como a aplicação dos recursos do FPM em relação aos investimentos para a obtençâo de convergência dos níveis de desenvolvimento nas diversas regiốes paranaenses examinadas.

De um universo de 399 municípios paranaenses, a amostra para esta pesquisa compreendeu $349^{4}$ municípios, analisados entre 2002 e 2013. Ela foi colhida no Relatório de Finanças da Secretaria do Tesouro Nacional (STN-FINBRA), no Instituto Paranaense de Desenvolvimento Econômico e Social (IPARDES), no Instituto Brasileiro de Geografia e Estatística (IBGE) e na base de dados do Instituto de Pesquisa Econômica Aplicada (IPEADATA). Em virtude da disponibilidade de dados para o Índice IPARDES de Desempenho Municipal (IPDM), serão apresentadas as análises para os anos de 2002, 2005, 2007, 2008, 2009, 2010, 2011, 2012 e 2013.

O modelo econométrico de regressão foi calculado no software Stata 13. Objetiva-se, por meio de sua estimação, analisar os efeitos do grau de dependência das transferências do FPM, assim como das despesas com investimento sobre a taxa de crescimento do desenvolvimento dos municípios paranaenses entre 2002 e 2013.

A seguir, é apresentado um quadro com as variáveis, descriçốes e fontes utilizadas:

Quadro 1: Descrição e fonte das variáveis do modelo

\begin{tabular}{|l|l|c|}
\hline Variáveis & \multicolumn{1}{|c|}{ Descrição } & Fonte \\
\hline txipdm & $\begin{array}{l}\text { Taxa de crescimento do Índice IPARDES de Desempenho Muni- } \\
\text { cipal: calculada pela razáo do IPDM no ano de 2013 pelo IPDM } \\
\text { no ano de 2002. }\end{array}$ & IPARDES \\
\hline ipdm & Índice IPARDES de Desempenho Municipal. & IPARDES \\
\hline depfpm & $\begin{array}{l}\text { Grau de dependência dos orçamentos municipais com relação às } \\
\text { transferências do FPM: calculado por meio da divisão entre a recei- } \\
\text { ta do FPM sobre a receita corrente líquida dos municípios. }\end{array}$ & FINBRA \\
\hline depdiscrí 5 & $\begin{array}{l}\text { Grau de dependência dos orçamentos municipais com relação às } \\
\text { transferências discricionárias: calculado por meio da divisão entre } \\
\text { a receita do total de transferências discricionárias sobre a receita } \\
\text { corrente líquida dos municípios. }\end{array}$ & FINBRA \\
\hline inv & $\begin{array}{l}\text { Despesas com investimento dividido pela população total dos } \\
\text { municípios. }\end{array}$ & FINBRA \\
\hline renda & Produto Interno Bruto dividido pela população total dos municípios. & IPEADATA \\
\hline urb & $\begin{array}{l}\text { Taxa de urbanização: calculada pela razão entre a população resi- } \\
\text { dente em zona urbana e a população total. }\end{array}$ & IBGE \\
\hline pop & Total da população municipal. & IBGE \\
\hline
\end{tabular}

Fonte: Elaborado pelas autoras.

As variáveis contínuas foram corrigidas pela população e estão em sua forma logarítmica. Sendo assim, as estimativas geram diretamente os coeficientes de elasticidade. Os valores foram corrigidos a preços de dezembro de 2014, utilizando como deflator o Índice Geral de Preços (IGP-DI) da Fundação Getúlio Vargas.

Ressalte-se que foram analisados os efeitos das variáveis explicativas no ano
4 De um total de 399 municípios paranaenses, 349 forneceram dados para as variáveis estudadas durante o período de avaliação.

5 Exemplos de transferências discricionárias: Transferências a consórcios públicos; Transferências de convênios relativas ao - Sistema Único de Saúde (SUS); Transferências de Convênios da União Destinadas a Programas de Assistência Social; entre outras. 
6 Esse modelo fundamentase na adaptação dos estudos empíricos de Barro e Sala -i-Martin (1992) e Ferreira Júnior e Diniz (2014).
7 A interpretação dos coeficientes de modelos log-lineares é feita em variação percentual. inicial do período tomado como base de estudo (2002) sobre a taxa de crescimento da variável resposta no período da pesquisa (entre 2002 e 2013). Foram consideradas relaçóes temporais distintas, isto porque, mediante aprovaçóes e execuçóes orçamentárias, as transferências de recursos e os investimentos são açóes passíveis de alteração no curto prazo. Dessa maneira, os efeitos das variáveis depfpm, depdiscri e inv na variável resposta de nível de desenvolvimento municipal podem ser observados a longo prazo. Ademais, o montante impactado depende de outras características municipais, como renda per capita, taxa de urbanização e nível populacional.

Considerando isso, foi adotado o modelo a seguir ${ }^{6}: \ln (\text { txipdm })_{i t}=\beta_{0}+\beta_{1}$ $\ln (\mathrm{ipdm})_{\mathrm{it}}+\beta_{2} \operatorname{depfpm}_{\mathrm{it}}+\beta_{3}$ depdiscri $_{\mathrm{it}}+\beta_{4} \ln (\mathrm{inv})_{\mathrm{it}}+\beta_{5} \ln (\text { renda })_{\mathrm{it}}+\beta_{6} \mathrm{urb}_{\mathrm{it}}+\beta_{7}$ $\ln (\text { pop })_{\text {it }}+u_{i}(1)$, em que:

txipdm: variável a ser explicada no modelo que mede a taxa de crescimento do IPDM entre 2002 e 2013 - esse índice foi utilizado como proxy de desenvolvimento dos municípios paranaenses;

ipdm: variável independente que mede o nível de desenvolvimento dos municípios paranaenses em 2002. Espera-se um efeito negativo na variável explicada, indicando uma tendência de convergência nos níveis de desenvolvimento dos municípios ao longo do tempo;

depfpm: variável independente que indica o grau de dependência dos orçamentos municipais com relação ao FPM em 2002. O efeito dessa variável no desenvolvimento é positivo, se a transferência tiver incentivado o desenvolvimento municipal, caso contrário, o impacto de depfpm na variável dependente é negativo;

depdiscri: variável independente que mensura o grau de dependência dos orçamentos municipais com relação às transferências discricionárias da União para os municípios, em 2002. Do mesmo modo que no $\operatorname{depfpm}$, o efeito dessa variável na taxa de crescimento do IPDM é positivo, se for constatado que tais transferências têm incentivado o desenvolvimento municipal, do contrário, haverá um impacto negativo de depdiscri na variável dependente;

inv: variável independente que mede o total de despesas com investimento per capita dos municípios paranaenses para 2002. Há a expectativa de um impacto positivo na variável explicada, tendo em vista que, quanto mais os municípios despendem com investimentos, maior é o desenvolvimento local.

Ademais, foram utilizadas as seguintes variáveis explicativas de controle do município $i$, no período $t=2002$ : renda, taxa de urbanização $(u r b)$ e população do município (pop).

Os termos $i$ e $t$ representam, respectivamente, os municípios paranaenses e o período de tempo analisado. $\beta 0, \ldots, \beta 6$ são os parâmetros do modelo de regressão; e u $i$ refere-se aos erros da regressão, com as pressuposições estatísticas usuais.

A denotaçáo "In" significa que foi aplicado o logaritmo neperiano na variável dependente e nas variáveis independentes contínuas, obtendo modelos log-lineares ${ }^{7}$, que foi a forma funcional que se apresentou mais adequada para o estudo. Os valores de variáveis como Produto Interno Bruto, investimentos e população tendem a ser assimétricos; transformaçôes logarítmicas desse tipo de variável reduzem tanto a assimetria quanto a heterocedasticidade. Segundo Wooldridge (2005), variáveis que são estritamente positivas possuem distribuiçôes heterocedásticas; esse problema pode ser aliviado, se náo eliminado, pelo uso do logaritmo neperiano. Além disso, o uso do ln 
"estreita a amplitude dos valores das variáveis, em alguns casos em quantidade considerável. Isso torna as estimativas menos sensíveis a observaçóes díspares na variável dependente ou nas variáveis independentes" (WOOLDRIDGE, 2005, p. 181).

Os modelos foram estimados com as variáveis em sua forma original e foi aplicado o teste de MacKinnon, White e Davidson - MWD, proposto por Gujarati e Porter (2011), para a escolha entre os modelos linear e log-linear. Sob a hipótese nula do teste MWD, o modelo linear é o mais apropriado, já sob a hipótese alternativa, o modelo log-linear é o mais adequado. Como não foi possível rejeitar nenhum dos modelos, optou-se pelo que demonstrou um melhor ajustamento, parâmetros com sinais esperados e $\mathrm{R}^{2}$ ajustado e estatística F melhorada. De acordo com Wooldridge (2005), na escolha funcional do modelo, quando nenhum deles é rejeitado, pode-se utilizar o $\mathrm{R}^{2}$ ajustado na seleção.

Os gráficos de dispersão foram construídos utilizando-se o corte mesorregional dos municípios paranaenses. Dez mesorregióes pertencem ao Estado do Paraná, a saber: Centro Ocidental, Centro Oriental, Centro-Sul, Metropolitana de Curitiba, Noroeste, Norte Central, Norte Pioneiro, Oeste, Sudeste e Sudoeste. Foram expurgados das mesorregiôes e analisados separadamente, os munícipios que se apresentaram como outliers nas análises, pois possuíam características distintas das demais unidades municipais, como maior nível populacional ${ }^{8} \mathrm{e}$ indícios de maior desenvolvimento. São eles: Cascavel, Colombo, Curitiba, Foz do Iguaçu, Guarapuava, Londrina, Maringá, Ponta Grossa e São José dos Pinhais.

O IPDM foi utilizado como uma proxy de desenvolvimento municipal. Esse índice mede o desempenho da gestão e de açôes públicas dos 399 municípios do Estado do Paraná, considerando três dimensões: renda, emprego e agropecuária, saúde e educação. Sua elaboração baseia-se em diferentes estatísticas de natureza administrativa disponibilizadas por entidades públicas. Ele varia de 0 a 1, apresentando, respectivamente, a condição mínima e máxima de desenvolvimento. Sua elaboração é feita pelo Instituto Paranaense de Desenvolvimento Econômico e Social.

O grau de dependência das transferências municipais é calculado a partir da divisão do FPM pela Receita Corrente Líquida (RCL) dos municípios. A relação FPM/Investimentos indica a porcentagem de receita do FPM com relação às despesas com investimento dos municípios.

Os gráficos de dispersão foram construídos para os anos de 2002, 2005, 2007, 2008, 2009, 2010, 2011, 2012 e 2013. Eles relacionam, em um primeiro momento, o IPDM com o FPM/RCL e, por conseguinte, o IPDM com o FPM/Investimento.

A fim de dar suporte e facilitar as análises, os gráficos foram divididos em quatro quadrantes: I, II, III e IV. Essa nomenclatura foi estabelecida com vistas a fazer um estudo mais detalhado dos dados, a partir do qual foi possível demonstrar a posição e classificar as mesorregióes e os municípios de acordo com seu nível de desenvolvimento, grau de dependência das transferências e relação FPM/Investimento. Os quadrantes foram conceituados da seguinte maneira:

i. Quadrante I - alto grau de desenvolvimento e baixa relação do FPM/RCL. As mesorregiôes e municípios que se situam nesse quadrante retratam níveis significantes de desenvolvimento, associados com baixo grau de dependência do FPM no seu orçamento;

ii. Quadrante II - alto grau de desenvolvimento e alta relação do FPM/RCL. Esse quadrante caracteriza níveis altos de desenvolvimento, porém, com grau de dependência do FPM inferior à média paranaense;
8 Como critério, foram expurgadas a capital e cidades com população superior a 150 mil habitantes. 
iii. Quadrante III - baixo grau de desenvolvimento e baixa relação FPM/RCL. Expressam-se, nesse quadrante, os níveis baixos de desenvolvimento, entretanto, o grau de dependência é superior à média do Paraná;

iv. Quadrante IV - baixo grau de desenvolvimento e alta relação FPM/RCL. As mesorregiôes e municípios presentes nesse quadrante possuem os resultados mais inferiores do Estado, pois têm níveis de desenvolvimento abaixo da média estadual, com alto grau de dependência do FPM.

A Figura 1 mostra a matriz dos gráficos com as posiçôes dos quadrantes determinadas.

Figura 1: Matriz dos gráficos com determinação dos quadrantes

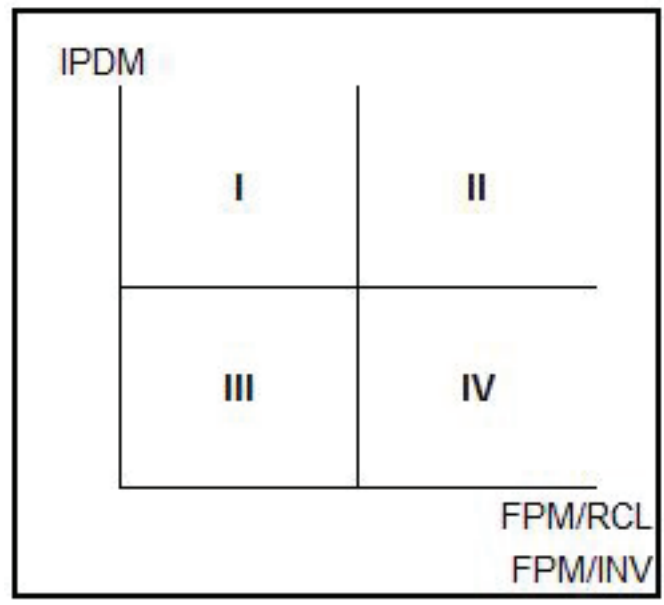

Fonte: Elaborado pelas autoras.

Com a interpretação dos resultados, pretende-se observar o grau de dependência do Fundo de Participação dos Municípios associado ao desenvolvimento regional e, por conseguinte, relacioná-lo ao sistema político multinível.

\section{RESULTADOS E ANÁLISES}

\section{ANÁLISE dA RELAÇÃo ENTRE O IPDM COM O GRAU DE DEPENDÊNCIA DAS TRANSFERÊNCIAS E COM A PROPORÇÃO DO FPM SOBRE OS INVESTIMENTOS NAS MESORREGIÕES PARANAENSES}

A avaliação das mesorregióes e municípios do Paraná com mais de 150.000 habitantes permitiu chegar aos resultados apresentados a seguir.

Quadro 2: Legenda referente aos gráficos de dispersão

\begin{tabular}{|c|c|c|c|c|c|}
\hline$\bullet$ & Centro Ocidental & $\bullet$ & Noroeste & - & Sudeste \\
\hline$\bullet$ & Centro Oriental & - & Norte Central & - & Sudoeste \\
\hline$\bullet$ & Centro-Sul & - & Norte Pioneiro & $\bullet$ & Municípios outliers \\
\hline 0 & Metropolitana de Curitiba & $\bullet$ & Oeste & • & Ponto médio \\
\hline
\end{tabular}

Fonte: Elaborado pelas autoras. 
Figura 2: IPDM versus grau de dependência nas mesorregióes paranaenses e municípios acima de 150.000 habitantes
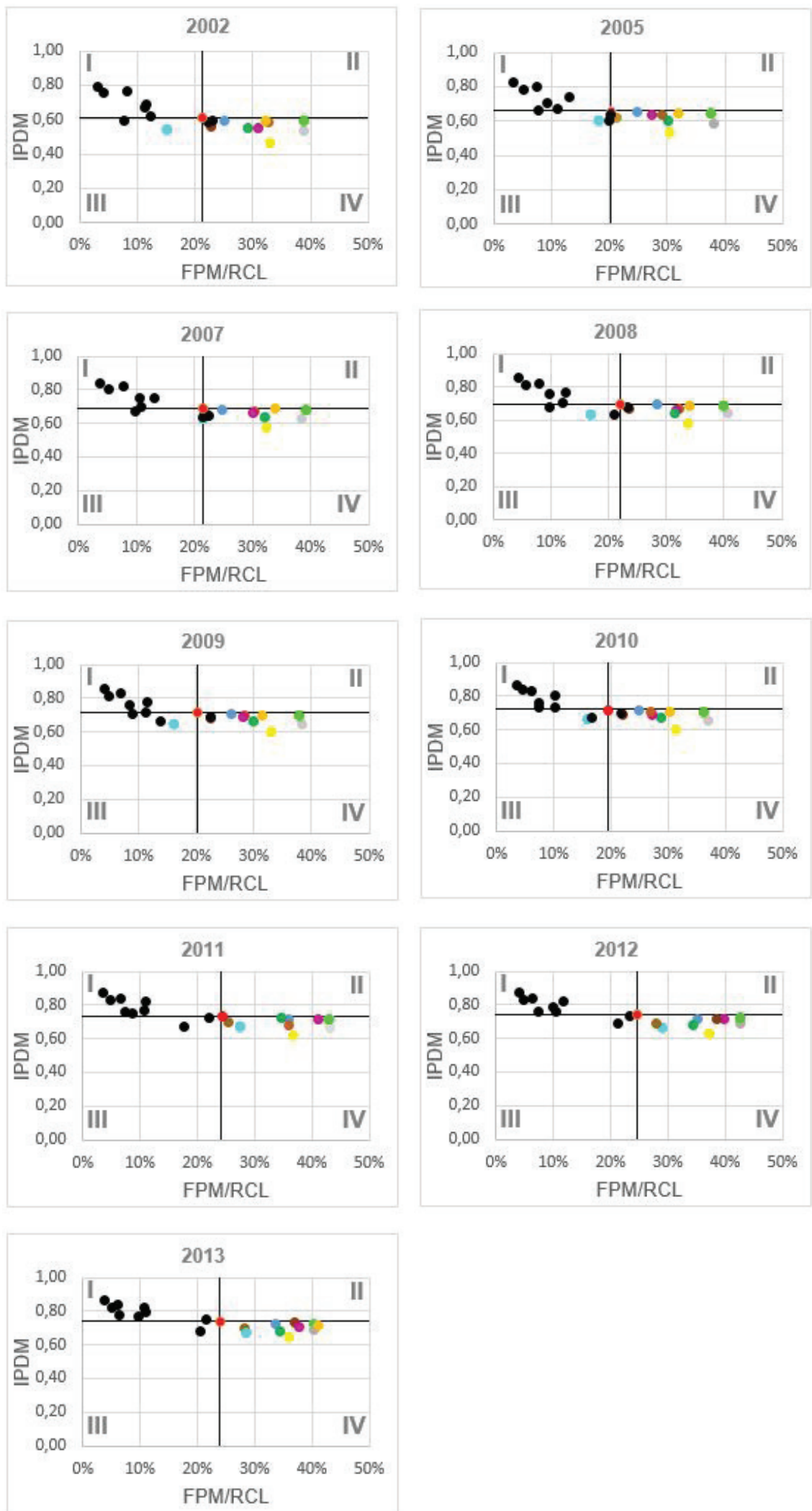

Fonte: Elaborado pelas autoras com base nos dados do FINBRA e IPARDES. 
A performance dos dados é relativamente estática ao longo dos anos; há pequenas variaçôes, mas os dados se mantêm na mesma proporção. Há uma concentração dos municípios e das mesorregiôes nos quadrantes I e IV, nos quais os maiores municípios (marcadores na cor preta) estão mais bem colocados em relação à média estadual, pois encontram-se, em sua maioria, aglomerados no quadrante I, expressando níveis significantes de desenvolvimento associado com baixo grau de dependência do FPM no seu orçamento. Em contrapartida, as mesorregióes (marcadores coloridos) concentram-se, em sua pluralidade, no quadrante IV, evidenciando, assim, um cenário de dependência e de baixo desenvolvimento.

Essas disparidades ficam ainda mais nítidas quando se analisa a situação de forma desagregada. Entre os nove maiores municípios avaliados, é possível observar que, em média, eles apresentaram um grau de dependência de 10,95\% e IPDM de 0,74. Isso pode ser ilustrado a partir dos índices da capital do estado, Curitiba, que revelou em 2002 o menor grau de dependência em todo o período de análise $(3,16)$ e em 2010 o melhor IPDM $(0,87)$. Todavia, situação oposta é verificada em Colombo e Guarapuava, que ficaram nos quadrantes III ou IV em todos os anos estudados, indicando alto grau de dependência e baixos índices de desenvolvimento.

Considerando-se as mesorregióes, a maioria dos pontos se concentra no IV quadrante. Nesse grupo, tem-se o maior grau de dependência do FPM e o mais baixo nível de desenvolvimento; a média desses indicadores é de 29,59\% e 0,64, respectivamente. As Regiōes Metropolitana de Curitiba (marcador azul-claro) e Oeste (marcador azul-escuro) denotam os melhores resultados relativos à média, ao passo que a Norte Pioneiro (marcador lilás) e a Centro-Sul (marcador amarelo) exibiram os piores números. Em 2008, por exemplo, a Norte Pioneiro apresentou o maior grau de dependência do FPM entre todas as mesorregiôes (40,68\%).

Os dados evidenciam a existência de um padrão heterogêneo entre os casos analisados, ficando claro que há dois conjuntos de municípios no Paraná: o conjunto daqueles que possuem baixo grau de dependência frente às transferências e alto desenvolvimento, e o daqueles que têm alta dependência do FPM e não apresentam desenvolvimento significativo.

A partir da análise dos gráficos de dispersão, observa-se que quanto maior é o grau de dependência orçamentária das mesorregióes e municípios outliers em relação ao FPM, menor é o desenvolvimento dos entes federativos. Uma vez que o mecanismo de repasses de fundos públicos busca direcionar um volume proporcionalmente maior de recursos aos municípios menos desenvolvidos, ao estudar a associação entre essas duas variáveis - grau de dependência orçamentária e desenvolvimento municipal - no mesmo período de tempo, é esperado que a relação entre elas seja inversa.

Nesse sentido, é necessário verificar os efeitos da dependência das transferências no desenvolvimento municipal tomando períodos distintos de tempo. Visto que o IPDM é uma variável estrutural decorrente de múltiplos fatores e tendo, entre as diversas variáveis explicativas, as transferências de recursos como centrais neste estudo, deve-se considerar o fato de que os recursos recebidos no tempo $t$ causaráo impactos no desenvolvimento municipal no tempo $t+n$. Portanto, por meio da estimação do modelo econométrico descrito anteriormente, serão analisados os efeitos tanto da dependência do FPM quanto das despesas com investimentos no ano inicial do estudo sobre a taxa de crescimento do IPDM entre 2002 e 2013.

Com esses resultados, é possível concluir que as transferências desestimulam os 
entes federativos a maximizarem suas capacidades tributárias, implicando um maior grau de dependência orçamentária, o qual se mantém estático ao longo dos anos.

A seguir são apresentadas as análises a partir da relação do IPDM com a proporção do FPM no investimento das 10 mesorregióes e municípios com mais de 150.000 habitantes.

Figura 3: IPDM versus proporção do FPM sobre os investimentos nas mesorregiôes paranaenses e municípios acima de 150.000 habitantes
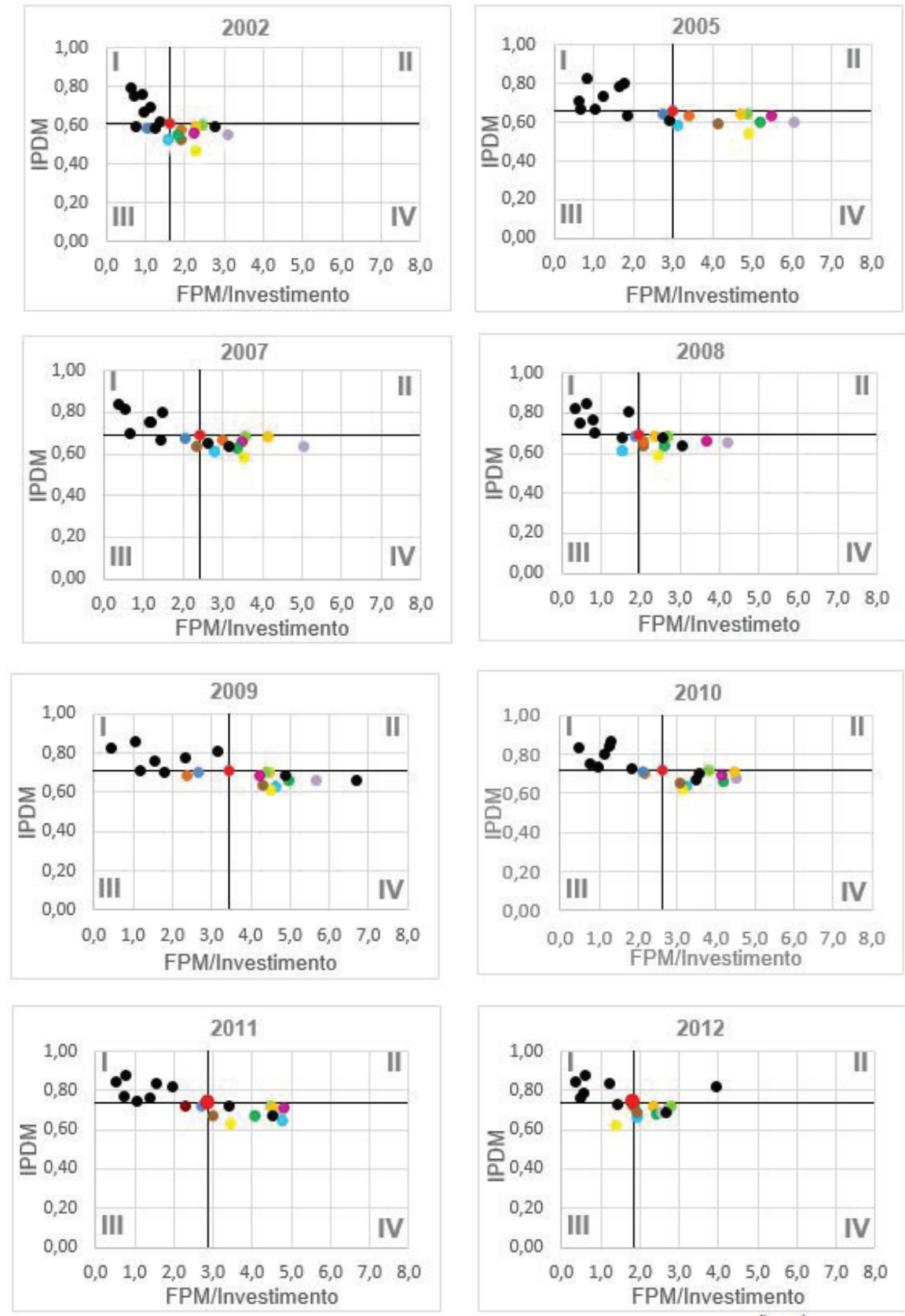

Fonte: Elaborado pelas autoras com base nos dados do FINBRA e IPARDES. 
Figura 3: IPDM versus proporção do FPM sobre os investimentos nas mesorregiôes paranaenses e municípios acima de 150.000 habitantes

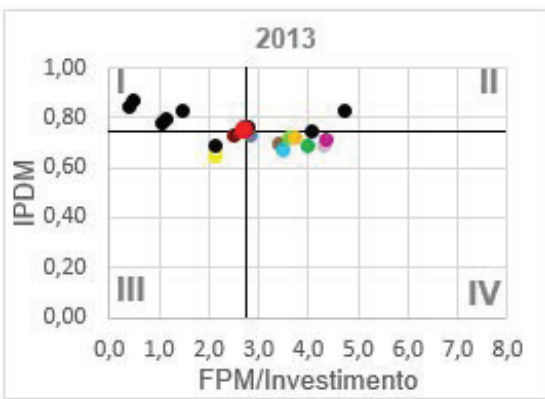

Fonte: Elaborado pelas autoras com base nos dados do FINBRA e IPARDES.

São observados alguns pontos em comum com as análises anteriores. Há uma relação inversa entre a proporção do FPM sobre o investimento com o IPDM, ou seja, quanto maior é a variável FPM/Investimento, menor é o desenvolvimento dos municípios da amostra. Percebe-se que há concentração dos dados nos quadrantes I e IV, evidenciando ainda mais a existência de dois grupos distintos no Estado do Paraná.

O quadrante I detém os maiores municípios. Em contraste, as mesorregióes concentram-se, em sua maioria, no IV quadrante. Fazendo-se uma análise mais desagregada, entre as mesorregióes, a Oeste (marcador azul-escuro) se destaca com os melhores resultados associados à média do Paraná, ficando no III quadrante em todos os anos. A Norte Pioneiro (marcador lilás), em 2005, apresenta a relação FPM/ Investimento mais alta de todo o período de análise $(6,04)$, ou seja, ela recebe seis vezes mais recursos do fundo em relação ao quanto investe e desenvolve-se relativamente pouco - seu IPDM nesse mesmo ano foi de 0,60. A Centro-Sul possui em 2002 o menor resultado quanto ao IPDM $(0,47)$ : a média é de 3,42 para o FPM/ Investimento e 0,64 para o IPDM. Situação inversa ocorre nos municípios de maior nível populacional (marcadores na cor preta), que têm média de FPM/Investimento e IPDM de 1,60 e 0,78, respectivamente. Curitiba e Maringá predominam com os melhores resultados, enquanto Colombo e Guarapuava movimentam-se, ao passar dos anos, para o quadrante IV, diminuindo gradativamente seus desempenhos.

Os resultados apontam uma dispersão dos dados; há movimentos de convergência e divergência em torno da média estadual. No período de estudo, ocorreram eleiçóes municipais em 2004, 2008 e 2012. É importante notar que os dados destacam uma convergência nos anos de eleiçôes municipais e nos períodos que as antecedem: nesses intervalos, a proporção do FPM sobre investimento é relativamente mais baixa. Em contrapartida, nos anos posteriores às eleiçôes, os dados tendem a se divergir, apresentando proporçôes maiores do FPM sobre o investimento. Isso evidencia um maior grau de investimentos em anos de eleiçôes do que nos anos subsequentes. Essa

9 Para uma revisão da literatura sobre a noção de ciclo eleitoral das políticas, cf. Nakaguma e Bender (2006). dinâmica pode ser explicada por indícios da existência de ciclo eleitoral das políticas ${ }^{9}$, em que o governo, por meio do aumento dos gastos públicos em investimento nos anos eleitorais ou em períodos antecedentes, pode sinalizar aos eleitores maior competência em obras visíveis a fim de vencer as eleiçóes.

Ao observar mais detalhadamente, percebe-se que em 2002 as mesorregióes e os municípios estáo bastante concentrados nas proximidades da média do Paraná (marcador vermelho) - o nível de FPM sobre o investimento varia em um intervalo 
de 0,61 e 3,10; em 2005, ano subsequente à eleição municipal, esses dados divergem em relação à média estadual e o FPM em relação ao Investimento varia de 0,64 a 6,04, o que demostra que os municípios passam a receber mais transferência em relação ao quanto estáo investindo. A análise de 2007 revela que os dados voltam a convergir gradativamente para a média, o que acontece até 2008 (ano de eleição municipal). Em 2009, novamente, verifica-se a dispersão dos dados, que voltam a convergir em 2010 e, principalmente, em 2012.

Sendo assim, os anos em que ocorreram eleiçóes (2004, 2008 e 2012) apresentaram uma menor relação entre a proporção do FPM sobre o investimento, causando uma consequente concentração dos dados em relação à média; nos anos subsequentes às eleiçôes, essa relação aumentou, o que traz indícios de que os investimentos foram pormenorizados. A partir disso, é possível evidenciar a formação de padrôes cíclicos associados ao comportamento das eleiçóes municipais.

Com base na análise teórica sobre sistema político multinível, pode-se postular que mecanismos de coordenação nacional que favoreçam a uniformidade dos serviços públicos prestados e equilibrem as formas de cooperação e competição entre os níveis de governo são necessários para impulsionar o desenvolvimento e a equiparação dos territórios nacionais. Regras de destinação das receitas, regulamentadas e fiscalizadas pela Uniâo, tendem a fomentar a homogeneidade dos gastos municipais; esse é um tipo de mecanismo relevante para o controle das despesas excessivas das jurisdiçóes, principalmente em períodos eleitorais. Embora não exista um vínculo mecânico entre eleiçóes e investimentos (MARQUES; BICHIR, 2001), os dados apresentados indicam que tal aspecto precisa ser levado em conta nas análises sobre decisóes governamentais na perspectiva do cálculo racional.

\section{EFEITOS DO GRAU DE DEPENDÊNCIA DAS TRANSFERÊNCIAS E DOS INVESTIMENTOS SOBRE O DESENVOLVIMENTO DOS MUNICÍPIOS PARA- NAENSES}

A seguir, são apresentadas algumas estimaçôes do modelo econométrico de regressáo utilizado para analisar os efeitos sobre a taxa de crescimento do IPDM exercidos pelo grau de dependência das transferências obrigatórias da União aos municípios, representadas pelo FPM, assim como pelas despesas com investimento. Primeiramente, foram aplicados testes estatísticos com a finalidade de detectar a presença de multicolinearidade e heterocedasticidade no modelo.

A fim de diagnosticar a existência de multicolinearidade entre as variáveis, foi utilizado o teste FIV (Fatores de Inflação da Variância). Valores de 1/FIV próximos de zero indicam multicolinearidade entre as variáveis. Como pode ser observado na tabela a seguir, todas as variáveis apresentaram valores de 1 /VIF próximos a 1 , sendo assim, não há indício desse problema no modelo adotado. 
Tabela 1: Resultado do teste VIF

\begin{tabular}{ccc}
\hline Variável & VIF & $\mathbf{1 / V I F}$ \\
\hline Ipdm & 1,40 & 0,7164 \\
depfpm & 2,46 & 0,4066 \\
depdiscri & 1,09 & 0,9183 \\
inv & 1,46 & 0,6863 \\
renda & 1,61 & 0,6216 \\
urb & 1,55 & 0,6454 \\
pop & 2,77 & 0,3611 \\
\hline
\end{tabular}

Fonte: Elaborado pelas autoras com base nas estimaçóes do software Stata.

Para identificar a presença de hetorecedasticidade, foi utilizado o teste de Breush Pagan Godfrey:

Tabela 2: Resultado do teste de Breush Pagan Godfrey

\begin{tabular}{cc}
\hline \multicolumn{2}{c}{ Heterocedasticidade } \\
\hline Breush Pagan & Prob $>\mathrm{chi}^{2}$ \\
\hline 17,24 & 0,000 \\
\hline
\end{tabular}

Fonte: Elaborado pelas autoras com base nas estimaçóes do software Stata. A hipótese nula indica que os erros são homocedásticos.

O teste de Breush Pagan apresentou presença de heterocedasticidade no modelo, pois a hipótese nula, isto é, de que os resíduos eram homocedástios, foi rejeitada. Diante disso, foram estimados os modelos pelo método MQO sobre erros padróes robustos. Esse procedimento visa a ajustar o desvio-padrão das variáveis a fim de corrigir a ausência de homocedasticidade dos resíduos da regressão. São expostos, abaixo, os resultados da estimação, seguindo o processo e a equaçáo já descritos:

Tabela 3: Estimação do modelo

\begin{tabular}{lcl}
\hline \multicolumn{1}{c}{ Variáveis Independentes } & \multicolumn{2}{c}{ txipdm } \\
\hline ipdm & $-0,5830$ & {$[-22,59]^{* * *}$} \\
depfpm & 0,0613 & {$[2,41]^{* *}$} \\
depdiscri & $-0,0006$ & {$[-0,04]$} \\
inv & 0,0167 & {$[3,02]^{* *}$} \\
renda & 0,0161 & {$[2,22]^{* *}$} \\
urb & $-0,0169$ & {$[-0,98]$} \\
pop & 0,0220 & {$[5,49]^{* * *}$} \\
constante & $-0,4607$ & {$[-6,7]^{* * *}$} \\
$\mathrm{R}^{2}$ ajustado & & 0,69 \\
F & & 85,93 \\
Prob $>$ F & & 0,0000 \\
Observações & & 349 \\
\hline
\end{tabular}

Fonte: Elaborado pelas autoras com base nas estimações do software Stata.

As estatísticas t encontram-se entre colchetes.

*** significativo a $1 \%$;

** significativo a $5 \%$. 
Concernente à robustez do modelo, o teste $\mathrm{F}$ para significância conjunta dos coeficientes apresentou resultado significativo. Excetuando-se as variáveis depdiscri e urb, que não foram estatisticamente significativas, o coeficiente individual das demais variáveis independentes foi significativo a $1 \%$ ou $5 \%$ e os sinais dos parâmetros corresponderam ao esperado. Ademais, o $\mathrm{R}^{2}$ ajustado da regressão foi satisfatório, indicando que o poder de explicaçáo do modelo era de $69 \%$.

A primeira variável independente, $i p d m$ no período de 2002, apresenta um efeito negativo na variável explicada, ou seja, um aumento do índice de desenvolvimento no ano inicial do período base ocasiona uma redução da taxa de crescimento do IPDM, o que, ao longo do tempo, indica uma tendência de aproximação dos níveis de desenvolvimento dos municípios paranaenses, tal como uma consequente redução das disparidades intermunicipais. Dito de outro modo, os municípios com menores índices de desenvolvimento revelam maiores taxas de crescimento do IPDM, se comparados aos municípios com maiores índices de desenvolvimento.

Por conseguinte, o parâmetro positivo da variável dep revela que os municípios com maior dependência dos seus orçamentos com relação às transferências obrigatórias, em 2002, denotam maiores taxas de crescimento do desenvolvimento municipal. Por outro lado, não se encontrou significância estatística da variável que mede os efeitos da dependência das transferências discricionárias. Diante disso, é possível inferir que o repasse de recursos obrigatórios aos municípios menos favorecidos e o consequente aumento do grau de dependência dessas transferências em tais entes federativos têm contribuído para a equiparação inter-regional das diversas municipalidades analisadas.

Do mesmo modo, a variável inv apresenta um impacto positivo na taxa de crescimento do IPDM, o que é esperado, uma vez que gastos nessa rubrica, que é o principal item das despesas com capital, incluindo, por exemplo, gastos com obras, instalaçóes e infraestrutura urbana, são despesas essenciais para a promoção do desenvolvimento municipal.

Por fim, com relação às variáveis de controle, o parâmetro da taxa de urbanização (urb) não foi significativo. Os parâmetros obtidos para as variáveis renda e pop apresentaram sinais positivos, isto indica que a taxa de crescimento do IPDM é maior nos municípios que inicialmente possuíam maior renda per capita e naqueles com maior nível populacional.

Os resultados vão ao encontro do que é previsto pela literatura. Autores como Arretche e Rodden (2004), Gibson, Calvo e Falleti (2004), Soares e Neiva (2011), entre outros, sustentam, em suas investigaçôes, que a característica redistributiva é pertinente nas transferências obrigatórias. Gibson, Calvo e Falleti (2004) encontraram uma relação negativa entre as variáveis gastos obrigatórios e pobreza, ao passo que, tal como neste estudo, não obtiveram uma relação significativa entre as variáveis gastos discricionários e variáveis que denotam uma melhora no desenvolvimento, como pobreza e renda per capita.

Conclui-se, pois, que o aumento do grau de dependência dos orçamentos municipais com relação ao FPM tem gerado um efeito positivo no crescimento da taxa do IPDM, o que denota a diminuição das desigualdades entre os diversos municípios analisados. Portanto, apesar da dependência das transferências obrigatórias, há uma contrapartida na utilização desses recursos pelos entes federativos na promoção do desenvolvimento local. 


\section{CONSIDERAÇÕES FINAIS}

O objetivo principal deste artigo foi analisar os efeitos sobre a taxa de crescimento do desenvolvimento municipal exercidos pelo grau de dependência das transferências intergovernamentais representadas pelo FPM e pelas despesas de investimento. Os dados apontam para o que é previsto na literatura especializada: uma trajetória cada vez mais de dependência das transferências, mas com a contrapartida de redução das desigualdades intermunicipais.

Ao analisar os gráficos de dispersão que denotam a relação entre as transferências obrigatórias, como foco no FPM, e o índice de desenvolvimento municipal, percebese uma relação negativa - o que era previsto, uma vez que as variáveis foram observadas no mesmo período de tempo e os efeitos das receitas de transferências municipais sobre o nível de desenvolvimento só podem ser sentidos a longo prazo. Também foi possível deduzir que não houve redução frente ao padrão de dependência, que se mantem estático ao longo do período de estudo, não proporcionando o padrão de convergência esperado. O grau de dependência do FPM deveria ser reduzido, porque esse fundo objetiva desenvolver os entes federativos menos favorecidos, promovendo a equiparação regional.

É possível inferir, pelo exposto, que as transferências intergovernamentais podem estar induzindo os gestores públicos a se apoiarem nelas, desestimulando a maximização das capacidades tributárias municipais. No entanto, outros fatores também contribuem para esse cenário de dependência; há que se considerar, por exemplo, os incentivos e as possíveis distorçôes sobre a qualidade da gestão pública. A eficiência da aplicação dos recursos e da arrecadação tributária são elementos que favorecem o equilíbrio socioeconômico entre os municípios; sendo assim, faz-se necessário o estímulo a uma gestáo pública eficiente tanto no emprego dos recursos advindos das transferências como na arrecadação de recursos próprios.

Com base na delimitação de espaços distribuída graficamente, ficou evidente que o Paraná possui dois conjuntos: os municípios com população acima de 150.000 e as 10 mesorregióes - esses dois grupos figuram as disparidades estaduais. Nas análises do primeiro conjunto de gráficos, os dados apresentaram um relativo padrão estático ao longo do período de estudo; quando foi feita uma investigação da ótica dos investimentos (segundo conjunto de gráficos), foram percebidos movimentos de convergência e divergência dos dados em torno da média estadual, sugerindo a existência de um padrão cíclico associado às eleiçôes municipais.

No modelo econométrico de regressáo, ao considerar períodos distintos para verificar os efeitos da dependência das transferências sobre a taxa de crescimento do IPDM, verificou-se uma relação positiva, em que um aumento da dependência do FPM no período inicial impactou em um aumento da taxa de crescimento do desenvolvimento dos municípios entre 2002 e 2013, o que possibilita a redução das desigualdades regionais - como dito, objetivo central do repasse de recursos públicos obrigatórios.

A partir dessas constataçóes e da abordagem teórica, este estudo ratifica a importância do papel regulatório do governo central como um meio de favorecer a cooperação entre jurisdiçôes e como um elemento fundamental na redução das desigualdades territoriais. Ele reitera, igualmente, a relevância da coordenação das ações dos níveis de governo - coordenação que deve levar em conta o equilíbrio entre cooperação 
e competiçáo para o alcance de fins comuns, uma vez que, de um lado, as decisóes compartilhadas entre os entes federativos proporcionam a diminuição das desigualdades territoriais e, de outro, as formas de competição favorecem a busca por inovação e por melhor desempenho das gestôes locais.

As políticas reguladas pela União demonstram um efeito de uniformidade dos gastos municipais. Todavia, sabe-se que, no Brasil, ainda há desafios no que se refere à aplicação do sistema político multinível; há deficiência de coordenação e articulação entre União, estados e municípios. Portanto, é notória a necessidade da integração das políticas em todos os níveis, a fim de promover investimentos que possibilitem a equiparação dos territórios.

Nesse sentido, uma importante análise futura pode ser a comparação do caso brasileiro com o de outros países com experiências de governos multiníveis e uma equiparação territorial, procurando relacionar e identificar formas de aplicabilidade e de melhoria dos mecanismos multiníveis na sociedade brasileira. Por fim, cumpre frisar que o governo multinível pode ter dispositivos de estímulo de políticas públicas visando à diminuição das desigualdades territoriais; por sua vez, a análise de mecanismos do sistema político multinível, como as transferências intergovernamentais, pode auxiliar em sua adoção no país e também na coordenação de políticas entre níveis de governo.

\section{REFERÊNCIAS}

ABRUCIO, F. A Coordenação Federativa no Brasil: a experiência do período FHC e os desafios do Governo Lula. Revista de Sociologia e Política, n. 24, p. 41-67, 2005. https:// doi.org/10.1590/s0104-44782005000100005

; FRANZESE, C. Federalismo e Políticas públicas: o impacto das relaçóes intergovernamentais no Brasil. In: ARAÚJO, M. F. I.; BEIRA, L. (Org.). Tópicos de Economia Paulista para Gestores Públicos. São Paulo: Ediçóes FUNDAP, 2007.

AMORIM NETO, O.; SIMONASSI, A. G. Bases Políticas Das Transferências Intergovernamentais No Brasil (1985-2004). Revista de Economia Politica, v. 33, n. 4, p. 704-25, 2013. https://doi.org/10.1590/s0101-31572013000400010

ARRETCHE, M. Quem taxa e quem gasta: a barganha federativa na federação brasileira. Revista de Sociologia e Politica, n. 24, p. 69-85, jun. 2005. https://doi.org/10.1590/ s0104-44782005000100006

Federalismo e igualdade territorial: uma contradição em termos? Revista Dados, v. 53, n. 3, p. 587-620, 2010. https://doi.org/10.1590/s0011-52582010000300003

; RODDEN, J. Política Distributiva Na Federação: Estratégias Eleitorais, Barganhas Legislativas e Coalizóes de Governo. Revista Dados, v. 47, n. 3, p. 549-76, 2004. https:// doi.org/10.1590/s0011-52582004000300004

BARRO, R. J.; SALA-I-MARTIN, X. Convergence. Journal of Political Economy, v. 100, n. 2, p. 223-251, abr. 1992. Disponível em: <http://www.columbia.edu/ xs23/papers/pdfs/ converg.pdf>. Acesso em: 31 maio 2017.

BLANCO GARCÍA, Á. D. et al. Distribución de competencias tributarias y financiación local en América Latina: un análisis comparado. Alcalá de Henares: IELAT, 2012 (Documentos de Trabajo IELAT, 42). Disponível em: <http://dspace.uah.es/dspace/ bitstream/handle/10017/21601/distribucion_blanco_IELATDT_2012_N42.pdf?sequence $=1 \&$ isAllowed $=y>$. Acesso em: 31 maio 2017 .

\begin{abstract}
Carin Caroline Deda é graduada em Ciências Econômicas pela Universidade Federal do Paraná (UFPR); mestra em Gestão Urbana pela Pontifícia Universidade Católica do Paraná (PUC-PR).

E-mail: caroline.deda@ yahoo.com.br

Samira Kauchakje é graduada em Ciências Sociais e mestra em Ciência Política pela Universidade Federal do Paraná (UFPR); doutora em Ciência Política pela Universidade Federal de São Carlos (UFSCar); professora titular no Programa de Pós-Graduação em Gestão Urbana (PPGTU) da Pontifícia Universidade Católica do Paraná (PUC-PR); professora colaboradora no Programa de Pós-Graduação em Ciência Política da UFPR. E-mail: skauchakje@gmail. com

Artigo recebido em 12 de setembro de 2016 e aprovado para publicação em 27 de maio de 2017
\end{abstract}


BREMAEKER, F. E. J. Reforma tributária: vantagem ou desvantagem para os municípios. Salvador: Transparência Municipal, 2011. Disponível em: <http://www.oim. tmunicipal.org.br/abre_documento.cfm?arquivo=_repositorio/_oim/_documentos/ E2197D39-D92A-AA47-A921B9958CD4ACCE03102011094320.pdf\&i=1543>. Acesso em: 31 maio 2017.

BRITO, J. R. S.; MATOS FILHO, J.; COSTA, E. M. Análise das transferências intergovernamentais e seus efeitos nas finanças públicas dos municípios do Rio Grande do Norte (2001 - 2010). Revista Econômica do Nordeste, v. 45, n. 1, p. 47-62, jan./mar. 2014. Disponível em: <https://ren.emnuvens.com.br/ren/article/view/63>. Acesso em: 31 maio 2017.

ESTEBAN-LALEONA, S.; FRUTOS-MADRAZO, P.; MIGUEL-BILBAO, M. C. A Review of the empirical literature about the relationship between fiscal decentralization and economic growth. Economía, Sociedade y Territorio, v. 11, n. 36, p. 349-381, 2011. Disponível em: <http://www.scielo.org.mx/pdf/est/v1ln36/v11n36a4.pdf>. Acesso em: 31 maio 2017.

FERREIRA JÚNIOR, S.; DINIZ, J. S. Desigualdades na oferta municipal de serviços da atençâoo primária no estado de Minas Gerais: uma análise dinâmica entre os anos de 2007 e 2012. In: ENCONTRO NACIONAL DE ECONOMIA DA SAÚDE, 11., Rio de Janeiro, 2014. Anais... Rio de Janeiro: ABRES, 2014. Disponível em: <http://www. fjp.mg.gov.br/index.php/docman/publicacoes-spp/526-36-abres-2014-juliana-e-silvio/ files. Acesso em: 31 maio 2017.

GASPARINI, C. E.; MIRANDA, R. B. Evolução dos aspectos legais e dos montantes de transferências realizadas pelo Fundo de Participação dos Municípios. Brasília: IPEA, dez. 2006 (Texto para Discussão, 1243). Disponível em: <http://www.ipea.gov.br/portal/images/ stories/PDFs/TDs/td_1243.pdf>. Acesso em: 31 maio 2017.

GIBSON, E. L.; CALVO, E. F.; FALLETI, T. G. Reallocative Federalism: Legislative Overrepresentation and Public Spending in the Western Hemisphere. In: GIBSON, E. L. (Ed.). Federalism and Democracy in Latin America. Baltimore: Johns Hopkins University Press, 2004. p. 173-196.

GUJARATI, D.; PORTER, D. C. Econometria Básica. 5. ed. Rio de Janeiro: Elsevier, 2011.

MARQUES, E.; BICHIR, R. Investimentos públicos, infraestrutura urbana e produção da periferia em São Paulo. Espaço \& Debates, n. 42, p. 9-30, 2001.

MENDES, M.; MIRANDA, R. B.; COSIO, F. B. Transferências Intergovernamentais no Brasil: Diagnóstico e Proposta de Reforma. Brasília: Consultoria Legislativa do Senado Federal, abr. 2008 (Textos para Discussão, 40). Disponível em: <https://www12. senado.leg.br/publicacoes/estudos-legislativos/tipos-de-estudos/textos-para-discussao/ td-40-transferencias-intergovernamentais-no-brasil-diagnostico-e-proposta-de-reforma>. Acesso em: 31 maio 2017.

NAKAGUMA, M. Y.; BENDER, S. A emenda da reeleição e a Lei de Responsabilidade Fiscal: impactos sobre ciclos políticos e performance fiscal dos Estados (1986-2002). Economia Aplicada, v. 10, n. 3, p. 377-397, 2006. https://doi.org/10.1590/s141380502006000300005

PALOTTI, P. L. M.; COSTA, B. L. D. Relações intergovernamentais e descentralização: Uma análise da implementação do SUAS em Minas Gerais. Revista de Sociologia e Politica, v. 19, n. 39, p. 211-235, jun. 2011. https://doi.org/10.1590/s0104-44782011000200015

PRADO, S. Transferências Fiscais e Financiamento Municipal no Brasil. São Paulo: [s.n.], jul. 2001. Disponível em: <http://www.bndes.gov.br/SiteBNDES/export/sites/default/ bndes_pt/Galerias/Arquivos/bf_bancos/e0001710.pdfhtm>. Acesso em: 31 maio 2017.

A Questão Fiscal na Federação Brasileira: Diagnósticos e Alternativas. Brasília: IPEA, CEPAL, mar. 2007. Disponível em: <http://igepp.com.br/uploads/arquivos/ igepp_-_a_questao_fiscal_na_federacao_brasileira.pdf>. Acesso em: 31 maio 2017. 
SOARES, M. M.; NEIVA, P. Federalism and Public Resources in Brazil: Federal Discretionary Transfers to States. Brazilian Political Science Review, v. 5, n. 2, p. 94-116, 2011. Disponível em: <http://www.bpsr.org.br/index.php/bpsr/article/view/127>. Acesso em: 31 maio 2017.

SOUSA, A. L. R.; ARANTES, E. C. FPM: Importância, dependência e o impacto das reduçóes para o município de Boa Vista-RR - Uma análise do período de 2001 a 2011. Revista de Administração de Roraima, v. 2, n. 2, p. 51-69, 20 sem. 2012. https://doi. org/10.18227/rarr.v2i2.1138

SOUZA, C. Federalismo e Conflitos Distributivos: Disputa dos Estados por Recursos Orçamentários Federais. Revista Dados, v. 46, n. 2, p. 345-384, 2003. https://doi. org/10.1590/s0011-52582003000200006

- Governos Locais e gestão de políticas locais universais. São Paulo em Perspectiva, v. 18, n. 2, p. 27-41, dez. 2004. https://doi.org/10.1590/s0102-88392004000200004

TURGEON M.; CAVALCANTE P. Desproporcionalidade da Representação dos Estados no Congresso Nacional e seus Efeitos na Alocação dos Recursos Federais. Brasília: IPEA, jun. 2014 (Texto para Discussão, 1980). Disponível em: <http://www.ipea.gov.br/portal/ images/stories/PDFs/TDs/td_1980.pdf>. Acesso em: 31 maio 2017.

WOOLDRIDGE, J. M. Introdução à econometria: Uma abordagem moderna. São Paulo: Thomson, 2005. 